\title{
Finance Teaching and Research after the Global Financial Crisis
}

\author{
Jayanth R. Varma
}

W.P. No. 2011-03-02

March 2011

The main objective of the working paper series of the IIMA is to help faculty members, research staff and doctoral students to speedily share their research findings with professional colleagues and test their research findings at the pre-publication stage. IIMA is committed to maintain academic freedom. The opinion(s), view(s) and conclusion(s) expressed in the working paper are those of the authors and not that of IIMA.

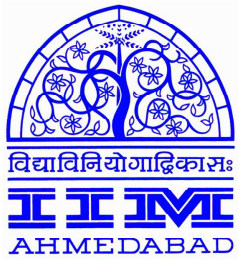

\section{INDIAN INSTITUTE OF MANAGEMENT AHMEDABAD-380 015 INDIA}




\title{
Finance Teaching and Research after the Global Financial Crisis
}

\author{
Jayanth R. Varma ${ }^{*}$
}

\begin{abstract}
Finance has come in for a great deal of criticism after the global financial crisis of 2007 and 2008. Clearly there were serious problems with finance as it was practiced in the years before the crisis. To the extent that this was only a gap between theory and practice, there is a need for finance practice to go back to its theoretical roots. But there is a need to re-examine finance theory itself.

The paper begins with an analysis of what the crisis taught us about preferences, probabilities and prices, and then goes on to discuss the implications for the models that are used in modern finance.

The paper concludes that the finance curriculum in a typical MBA programme has not kept pace with the developments in finance theories in the last decade or more. While a lot needs to change in finance teaching, finance theory also needs to change though to a lesser extent. Many ideas that are well understood within certain subfields in finance need to be better assimilated into mainstream models. For example, many concepts in market microstructure must become part of the core toolkit of finance. The paper also argues that finance theory needs to integrate insights from sociology, evolutionary biology, neurosciences, financial history and the multidisciplinary field of network theory. Above all, finance needs more sophisticated mathematical models and statistical tools.
\end{abstract}

\footnotetext{
* Professor, Indian Institute of Management, Ahmedabad 380 015, India. Email: jrvarma@iimahd.ernet.in
} 


\section{Finance Teaching and Research after the Global Financial Crisis}

\section{Introduction}

The global financial crisis of 2007 and 2008 (see Rajan, 2010, Roubini and Mihm, 2010 and Shiller, 2008) provides an opportunity for all finance professionals to introspect about the changes that need to be made in their discipline. Economists in general and financial economists in particular have come in for a great deal of criticism after the crisis. One well known book about the crisis was entitled "ECONned" (Smith, 2010), while a widely read columnist talked about the "formula that killed the world" (Salmon, 2009).

It is difficult to deny that there were serious problems with finance as it was practiced in the years before the crisis. Whether this was only a gap between theory and practice or whether there are fundamental problems in finance theory itself is a more difficult question. Even if the problems are only with the practice and not with the theory, finance academics must revisit how finance is taught so that these problems do not recur. If there are problems in finance theory itself, then finance academics must reflect on the directions that finance research should take to redress these problems.

This paper is the result of my own introspection about these issues. A lot of it has to do with how finance ought to be taught, but a significant part is also about how finance theory needs to change by drawing on insights from other disciplines.

The next section of this paper discusses what the crisis taught us about the 3 P's of finance individuals' preferences, their assessment of probabilities and the behaviour of market prices. Section 3 discusses the nature of changes that need to be made in the models that are used in modern finance. Section 4 is about the need for finance to integrate insights from other source disciplines. The last section presents the conclusions from the paper.

\section{Preferences, Probabilities and Prices}

\subsection{How the crisis changed the 3 P's}

It is the interactions among the $3 \mathrm{P}$ 's - preferences, probabilities and prices - that give modern financial economics its richness and depth (Lo, 1999 and 2004). The global financial crisis has given us sufficient reason to rethink many of our ideas on each of these three.

If we consider preferences, it is hard to believe that the average risk aversion of investors remained the same before, during and after the crisis. Moreover, fundamental theoretical models based on evolutionary psychology also require us to take time varying risk aversion quite seriously.

Turning to probabilities, the crisis forces us to accept that because of regime changes, statistical parameters are always estimated with very wide confidence bands. While finance theory has always been based on subjective probabilities, these have often been replaced by historical relative frequencies in practice. Finance practice needs to go back to its theoretical roots and embrace subjective probabilities as well as Bayesian statistics wholeheartedly.

When it comes to prices, we find many different conceptual approaches in modern finance. At one extreme, in many general equilibrium models with representative agents, prices arise not out of people trading with each other, but out of people optimizing against their own budget constraints. In fact, in these models, no trades take place at all and the prices are more in the nature of shadow prices. At the other extreme, in market microstructure theories, traded prices are the outcome of a complex interaction of quotes and orders, and do not necessarily represent equilibrium prices. The traded price 
can move from the ask price to the bid price without any change in the equilibrium price. The global financial crisis showed that the microstructure view of prices is extremely important even if we are only interested in the big picture - microstructure has macro consequences.

In the following sections, I elaborate on these ideas regarding preferences, probabilities and prices. Incorporating these ideas into finance teaching will hopefully lead to a richer and more nuanced understanding of the subject.

\subsection{Preferences: Risk aversion may be environment contingent}

Time varying risk aversion is usually frowned upon as a desperate attempt to reconcile a struggling theory with unfavourable evidence. It is true that time varying risk aversion can be abused to explain away many anomalies. For example, a stock market bubble can be explained away as a temporary decline in risk aversion, and similarly a temporary rise in risk aversion can explain away a market crash. Arbitrary time variation in risk aversion can thus ensure that many theories can never be falsified making them devoid of testable implications.

Many finance theorists have, however, gone to the other extreme of thinking of the risk aversion coefficient as an innate characteristic of a human being - almost as if there were a gene for risk aversion. It is true that there is a genetic element in risk aversion, but studies based on identical twins show that genetics explain only 20-30\% of the variation in risk aversion (Cesarini et al, 2009 and 2010). Evolutionary biology provides a theoretical argument why a large part of risk aversion may not be purely genetic. Bell (2007) puts it very succinctly: "If a trait is heritable and linked to survival or reproductive success, then evolutionary theory tells us that variation will eventually disappear from the population."

Evolutionary biologists explain risk aversion as resulting from different life-history strategies adopted in response to ecological pressures. In this sense, risk aversion is not so much an immutable trait as a (life-historical) strategic choice - for example, individuals with high future expectations (of evolutionary fitness) become more risk-averse than individuals with low expectations. (Wolf, 2007; Buss, 2009; and Heilbronner et al, 2008).

Incidentally, biologists do not regard risk aversion as being confined to human being or even to the higher primates. Kacelnik and Bateson (1996) review 59 different studies that demonstrate risk aversion in 28 different species of insects, birds and animals. Thus our understanding of risk aversion must be rooted in biology and not just in psychology.

If the degree of risk aversion is a strategic choice - the choice of a strategy for solving recurrent adaptive problems - then drastic shifts in the environment - the distribution of such adaptive problems - could conceivably cause change in these strategies. Booms and busts could then lead to (evolutionarily) rational changes in aggregate risk aversion. To push the analogy with Heilbronner $e t$ al (2008) to the level of caricature, one may suspect that human investors may (quite rationally!) behave like chimpanzees in booms and like bonobos during market crashes.

In particular, exceptionally loose monetary policy during a boom could change aggregate risk aversion as an (evolutionarily) rational response to altered expectations of future rates of return. The empirically observed yield seeking behaviour (shifting to higher risk assets to maintain portfolio yield levels) far from being irrational may in fact be ecologically rational when viewed as an environment contingent shift in life history strategies. Central banks may need to take this into account. 


\subsection{Probabilities: They are always subjective}

Finance courses necessarily build on what has been covered in the statistics courses. A course on portfolio theory, for example, would assume knowledge of the meaning of covariance. Unfortunately, there is a problem with this division of labour - most statistics professors teach classical statistics. That is true even of those statisticians who prefer Bayesian techniques in their research work!

The result is that many finance students wrongly think that when the finance theory talks of expected returns, variances and betas, it is referring to the classical concepts grounded in relative frequencies. Worse still, some students think that the means and covariances used in finance are sample means and sample covariances and not the population means and covariances.

In business schools like mine where the case method dominates the pedagogy, these errors are probably less (or at least do less damage) because in the case context, the need for judgemental estimates for almost everything of interest becomes painfully obvious to the students. The certainties of classical statistics dissolve into utter confusion when confronted with messy "case facts", and this is entirely a good thing.

But if cases are not used or used sparingly, and the statistics courses are predominantly classical, there is a very serious danger that finance students end up thinking of the probability concepts in finance in classical relative frequency terms.

Nothing could be farther from the truth. To see how differently finance theory looks at these things, it is instructive to go back to some of the key papers that established and developed modern portfolio theory over the years.

Here is how Markowitz (1952) begins his Nobel prize winning paper more than half a century ago:

"The process of selecting a portfolio may be divided into two stages. The first stage starts with observation and experience and ends with beliefs about the future performances of available securities. The second stage starts with the relevant beliefs about future performances and ends with the choice of portfolio."

Many finance students would probably be astonished to read words like observation, experience, and beliefs instead of terms like historical data and maximum likelihood estimates. This was the paper that gave birth to modern portfolio theory and there is no doubt in Markowitz' mind that the probability distributions (and the means, variances and covariances) are subjective beliefs and not classical relative frequencies.

Markowitz is also crystal clear that what matters is not the historical data but beliefs about the future historical data is of interest only in so far as it helps form those beliefs about the future.

Unless finance professors are willing to spend time in the class room discussing subjective probabilities, they must put pressure on the statistics professors to discuss probability from the subjective, Bayesian point of view. Finance students need to be confronted with probabilities that have no frequentist interpretation at all. For example, Borch (1976) tries to estimate the probability that the Loch Ness monster exists (and would be captured within a one year period) given that a large company had to pay a rather high premium of $0.25 \%$ to obtain a million pound insurance cover from Lloyd's of London against that risk. This is obviously a question which a finance student cannot refuse to answer; yet there is no obvious way to interpret this probability in relative frequency terms. 


\subsubsection{Expectations are heterogeneous}

The passage quoted above from Markowitz (1952) seems to take it for granted that different people will have different beliefs about the parameters of the subjective probability distribution of future returns.

Perhaps the seminal paper in finance to introduce the assumption that all investors have the same expectations was Sharpe (1964). To develop the Capital Asset Pricing Model (CAPM) that won him the Nobel prize, William Sharpe had to assume that all investors have the same beliefs so that he could determine the market equilibrium. But Sharpe (1964) made this assumption with great reluctance:

“... we assume homogeneity of investor expectations: investors are assumed to agree on the prospects of various investments - the expected values, standard deviations and correlation coefficients described in Part II. Needless to say, these are highly restrictive and undoubtedly unrealistic assumptions. However, ... it is far from clear that this formulation should be rejected - especially in view of the dearth of alternative models." (emphasis added)

While finance theory has been built on equilibrium models like the CAPM, the application of these models in investor decision making has always recognized the role of heterogeneous expectations. Treynor and Black (1973) interpreted the CAPM as saying that: "...in the absence of insight generating expectations different from the market consensus, the investor should hold a replica of the market portfolio." Treynor and Black devised an elegant and widely used model of portfolio choice when investors had out of consensus beliefs:

"The viewpoint in this paper is that of an individual investor who is attempting to trade profitably on the difference between his expectations and those of a monolithic market so large in relation to his own trading that market prices are unaffected by it."

Similar ideas can be seen in the popular Black Litterman model ("Global Portfolio Optimization," Financial Analysts Journal, September-October 1992). Black and Litterman started with the following postulates:

1. "We believe there are two distinct sources of information about future excess returns - investor views and market equilibrium."

2. "We assume that both sources of information are uncertain and are best expressed as probability distributions."

3. "We choose expected excess returns that are as consistent as possible with both sources of information."

Heterogeneous expectations arise naturally when there is inadequate data to estimate the requisite parameters with high accuracy. Even if long time series is available and the apparent sample size is very large, parameter estimates would be very imprecise if there are frequent regime changes. The global financial crisis has highlighted the importance of regime changes, and therefore forced us to recognize the imprecision in statistical parameter estimates. Parameter estimates must therefore be subjective, and expectations will be heterogeneous.

\subsubsection{Estimation must almost always be Bayesian}

The importance of Bayesian estimation of parameters can be illustrated nicely in terms of the CAPM beta, but the discussion is equally applicable to Fama-French multi-factor models, the Arbitrage Pricing Theory and several other models in modern finance theory. 
The derivation of the CAPM makes it clear that the beta is actually the ratio of a covariance to a variance and both of these are parameters of the subjective probability distribution that defines the market consensus. Statisticians instantly recognize that the ratio of a covariance to a variance is identical to the formula for a regression coefficient and are tempted to reinterpret the beta as such.

This may be formally correct, but it is misleading because it suggests that the beta is defined in terms of a regression on past data. That is not the conceptual meaning of beta at all. Rosenberg and Guy (1976) explained the true meaning of beta very elegantly in their paper introducing what are now called fundamental betas:

"It is instructive to reach a judgement about beta by carrying out an imaginary experiment as follows. One can imagine all the various events in the economy that may occur, and attempt to answer in each case the two questions: (1) What would be the security return as a result of that event? and (2) What would be the market return as a result of that event?"

This approach is conceptually revealing but is not always practical at this level of generality. The process of arriving at a usable estimate in practice may involve many sophisticated econometric procedures, but the purpose of all this econometrics is to provide a better foundation for our subjective belief about the true beta of a company based on at least the following inputs:

- The beta is equal to unity unless there is enough reason to believe otherwise. The value of unity (the beta of an average stock) provides an important anchor which must be taken into account even when there is other evidence. It is not uncommon to find that simply equating beta to unity outperforms the beta estimated by naive regression.

- What this means is that betas obtained by other means must be shrunk towards unity. An estimated beta exceeding one must be reduced and an estimated beta below one must be increased. One can do this through a formal Bayesian process (for example, by using a BayesStein shrinkage estimator), or one can do it purely subjectively based on the confidence that one has in the original estimate.

- The beta depends on the industry to which the firm belongs. Since portfolio betas can be estimated more accurately than individual betas, this is often the most important input into arriving at a judgement about the true beta of a company.

- The beta depends on the leverage of the company and if the leverage of the company is significantly different from that of the rest of the industry, this needs to be taken into account by unlevering and relevering the beta.

- The beta estimated by regressing the returns of the stock on the market over different time periods provides useful information about the beta provided the business mix and the leverage have not changed too much over the sample period. Since this assumption usually precludes very long sample periods, the beta estimated through this route typically has a large confidence band and becomes meaningful only when combined with the other inputs.

- Subjective beliefs about possible future changes in the beta because of changing business strategy or financial strategy must also be taken into account.

Much of the above discussion is valid for estimating Fama-French betas and other multi-factor betas, for estimating the volatility (used for valuing options and for computing convexity effects), for estimating default correlations in credit risk models and many other contexts.

Good classical statisticians are quite smart and in a practical context would do many of the things discussed above when they have to actually estimate a financial parameter. In my experience, they usually agree that (a) there is a lot of randomness in historical returns; (b) the data generating process does not remain unchanged for too long; (c) therefore in practice there is not enough data to avoid sampling error; and (d) hence it is desirable to use a method in which sampling error is curtailed by fundamental judgement. 
On the other side, Bayesians shamelessly use classical tools because Bayes theorem is an omnivore that can digest any piece of information whatever its source and put it to use to revise the prior probabilities. In practical terms, Bayesians and classical statisticians may end up doing very similar stuff.

The advantage of shifting to Bayesian statistics and subjective probabilities is primarily conceptual and theoretical. It would eliminate confusion in the minds of students on the ontological status of the fundamental constructs of finance theory.

\subsection{Prices: Market microstructure has macro consequences}

\subsubsection{At the microstructure level, there is no such thing as "the price."}

In discussions about price in market microstructure, the term price must be qualified to make clear what we are talking about. There is a bid price, there is an ask price, there is a mid price, there is a last traded price, and there is a volume weighted average price, but there is no such thing as "the price."

The most important prices in market microstructure are bid and ask prices which represent the prices at which one can sell and buy respectively. However, these are valid for relatively small quantities. For any person contemplating a medium size transaction, it is necessary to examine the entire order book to determine the price at which the transaction can be completed. For larger transactions, it is necessary to make an assessment of latent orders - bid and ask orders that are not currently in the order book - to determine the potential transaction price.

Consider for example, the following order book:

\begin{tabular}{|l|l|l|l|}
\hline \multicolumn{2}{|c|}{$\begin{array}{c}\text { Bid side } \\
\text { (orders to buy) }\end{array}$} & \multicolumn{2}{c|}{$\begin{array}{c}\text { Ask side } \\
\text { (orders to sell) }\end{array}$} \\
\hline Price & Quantity & Price & Quantity \\
\hline 99.00 & 250 & 100.00 & 200 \\
\hline 98.75 & 350 & 100.50 & 300 \\
\hline 98.50 & 300 & 101.00 & 450 \\
\hline 98.00 & 200 & 101.50 & 250 \\
\hline
\end{tabular}

The bid price is 99.00 and a seller can realize this price for up to 250 shares. The ask price is 100.00 and a buyer needs to pay this price for up to 200 shares. The mid price is 99.50 and is perhaps the closest that one can come to the concept of "the price."

For larger transactions, however, the price is quite different. A seller who wants to liquidate 1,000 shares will receive 99.00 for the first 250 shares, but will receive only 98.75 for the next 350 shares, 98.50 for the next 300 shares, and only 98.00 for the last 100 shares. The volume weighted average price is 98.66 .

A seller with 5,000 shares to sell must rely on the order book refreshing with new bids as the price falls to 98.00. These latent orders from value traders seeing a buying opportunity are the principal mechanism through which a large sale gets executed.

There will often be an intervening period, when 1,100 shares have been sold against the orders available in the order book, but value traders are still evaluating the situation and the latent orders have not materialized. At this point, the bid side of the order book is empty and the market is "ask only." There is no bid price, there is an ask price of 100.00 and there is a last traded price of 98.00. The concept of "the price" is even more elusive at this point. 
After several minutes, the sell order of 5,000 shares may finally get executed at a weighted average price of say 96.45. In other words, a large order can have a large "impact cost" and a long execution time.

For microstructure theorists, there is nothing unusual in all this; on the contrary, this is the normal state of affairs. During crises, this phenomenon can occur at a bigger scale and over longer periods. For example, in the dollar/yen exchange rate, the bid and ask prices may normally be separated by only a couple of cents. But during the dramatic events of October 8, 1998, the bid ask spread widened to 200 cents (the yen was bid at $¥ 113.50 / \$$ and asked at $¥ 111.50 / \$$ ). A prominent hedge fund manager complained to his investors that: "The yen, which was as liquid as water, suddenly dried up like the Sahara" (Mallaby, 2010, p 252).

During the global financial crisis, this phenomenon was witnessed on an even larger scale with entire markets freezing for extended periods of time. From a microstructure perspective, what is new is not the phenomenon itself, but its scale, scope and duration.

\subsubsection{Meltdowns happen all the time at the microstructure level}

At microstructure level, sharp and rapid price declines (market meltdowns) and the converse (meltups) happen all the time. For example, any sell order large enough to sweep through the whole or a major fraction of the bid side of the order book would cause a steep decline in prices within seconds (if not milliseconds). It might take several minutes for enough latent orders to enter the order book and reverse this meltdown. Conversely, a large buy order can send the price shooting upwards in the space of a few seconds or even milliseconds.

At the microstructure time scale, these "tail events" cause price movements that are several times the range that would be expected from a Gaussian" distribution. Microstructure theorists would not regard these markets as dysfunctional or irrational. On the contrary, what is important in this context is the self correcting ability of the market that restores equilibrium over the space of several minutes or hours. Taking into account the various frictions (search and information costs, transaction costs, and leverage restrictions), we should probably consider a market which experiences such microstructure meltdowns or meltups to be an efficient market.

During the crisis, booms and busts happened at a macro scale, but it is possible that the phenomenon differed from microstructure events only in their scale and duration.

\subsubsection{Is a financial crisis simply market microstructure writ large?}

These considerations lead us to consider the possibility that a financial crisis is simply market microstructure writ large. At the macro level, we tend to assume that "microstructure noise" has been washed out. It is then tempting to think of the market as being in continuous state of equilibrium rather than in a perpetual state of movement towards an ever changing equilibrium.

Perhaps, this is a mistake and the complexities of the microstructure world are present at longer time scales as well. This would of course imply that markets are messier and more complex than the ideal friction free market.

From a different perspective, however, the hypothesis that financial crisis is simply market microstructure writ large is very attractive. It means that we have the theoretical tools and techniques (of microstructure theory) to study crises.

\footnotetext{
*I think it is a good idea to consistently use the term "Gaussian distribution" instead of "normal distribution" to avoid the risk of students inadvertently and subconsciously associating non Gaussian distributions with some form of abnormality.
} 
At any rate, I think that all finance researchers must not only learn market microstructure theories, but also take them seriously as potential explanations for even macro scale phenomena.

\section{Models}

\subsection{Multi factor models are unavoidable}

\subsubsection{We must go beyond size and value}

While most introductory courses in financial markets and corporate finance are grounded in the CAPM, this is no longer the case in advanced courses in the MBA curriculum. Long ago, the Fama French three factor model replaced the CAPM as the workhorse for modelling asset returns when it comes to research in financial markets. Increasingly, this model is also the core model in elective courses in the MBA classroom. In recent years, the Fama French model has begun to give way to the Carhart four factor model which takes momentum into account. However, I think it is necessary to go beyond even this to consider liquidity as an explicit risk factor. Market, size, value, momentum, and liquidity are all essential to understand asset returns in the post crisis world.

\subsubsection{Liquidity is a systemic risk}

Though liquidity was studied as far back as the mid 1980s (Amihud and Mendelson, 1986), finance academics began to develop sophisticated models for liquidity risk only after the LTCM crisis in 1998. Most of the important advances in this field came in the mid 2000s well before the global financial crisis.

First of all, it became clear that liquidity was a systematic risk and not a diversifiable risk. The commonality that was found in liquidity made it possible to talk about liquidity betas and the liquidity risk premium in a way completely analogous to the corresponding notions for market risk (or the size and value factors). Pastor and Stambaugh (2003) and Acharya and Pedersen (2005) have established liquidity as a risk factor that needs to be considered alongside the conventional risk factors.

The second key advance was the theoretical linkage that was established between market liquidity and funding liquidity (Brunnermeier and Pedersen, 2007). Market liquidity which is all about market microstructure is intimately related to funding liquidity which is all about macroeconomics suddenly, micro has become macro!

An interesting application of including liquidity and other factors while evaluating the performance of an asset manager in a real world investment context is provided by Ang, Goetzmann and Schaefer (2009). Another interesting application is provided by Chen, Ibbotson, and Hu (2010).

\subsection{Microstructure needs agent based modelling}

Simple general equilibrium models relying on a representative investor typically assume homogeneous expectations. In these models, agents do not trade with each other - they only optimize against their budget constraints. There are no trades because the equilibrium price is defined as the price at which nobody wants to trade. The prices in these models are therefore more in the nature of shadow prices than real prices.

Of course, it is possible to build more complex models that allow two or three different types of agents with different information sets, but even these cannot capture the full range of heterogeneity that is apparent in real world financial markets.

Agent based models on the other hand allow arbitrary number of heterogeneous players with different information sets, trading strategies and objectives. Computer simulations are the principal tool 
because typically analytical solutions do not exist. The big advantage is that information aggregation and price discovery can be studied in detail, and the impact of alternative market microstructures can be quantified. A good example of this kind of work is Lee, Cheng and Koh (2010) who simulated a "flash crash" before it occurred on May 6, 2010 (in the US markets) using an agent based model.

If it is true that microstructure theories are relevant for understanding phenomena at macro time scales, then it is necessary to embrace agent based models in finance theory.

\subsection{Tail risk is the only real risk}

Way back in the 1960s, it was recognized that fat tails are pervasive in financial time series (Mandelbrot, 1963, Fama, 1963). But tail risk as the prepondarant form of priced risk has gained ground only in this century with the influential papers of Barro (2006) and Barro and Ursua (2009). Before the global financial crisis (and the associated Great Recession) it was widely believed that depressions were impossible (at least in developed markets) and it was easy to brush aside the idea that the Equity Risk Premium is compensation for tail risks like the Great Depression risk. Post crisis, this is a point of view that needs to be taken very seriously indeed.

Diversified portfolios can have tail risk only if stocks have common jumps or there is some other form of non linear dependence. Otherwise, the central limit theorem would imply that even if individual asset prices are fat tailed, the returns of diversified portfolios would be approximately Gaussian. Thus tail risk would require us to embrace not just fat tailed distributions, but non Gaussian copulas as well.

Quantitative models based on non Gaussian fat tailed distributions with non linear dependence structures (copulas) are hard from the point of view of teaching in the MBA classroom, but we must not shirk hard mathematics. Risk modelling using Value at Risk with Gaussian distributions and linear correlations is no longer defensible after all that we have seen during the global financial crisis (Varma, 2009).

\subsection{Efficient Market Hypothesis: There is still no free lunch}

We must distinguish between two important aspects of the efficient markets hypothesis (EMH) because the global financial crisis has led to diametrically opposite conclusions regarding these two perspectives:

- The first perspective is summarized by the statement that there is no free lunch or that it is not possible to beat the market in risk adjusted terms. If something is too good to be true, it is probably not true. The global financial crisis has strengthened this claim. All those apparently low risk, high return investments turned out to be high risk.

- The second perspective is that prices are "right" in the sense that they reflect fundamentals. The global financial crisis has weakened this claim. Many prices were clearly not right.

It is easy to reconcile these two lessons from the global financial crisis by drawing on the limits to arbitrage literature. Limits to arbitrage imply that prices are not always "right," but limits to arbitrage also tells us that the prices are wrong for a reason. The no free lunch argument remains true: there are anomalies, but no easily exploitable anomalies.

Another way of looking at it is that what appears like a free lunch is just the reward for a hidden tail risk. It is the unhedgeability of this risk (possibly a liquidity risk) that prevents arbitrageurs from correcting the anomaly. From a regulatory point of view, the important lesson is that a bank with implicit sovereign support will manufacture tail risk in order to exploit the apparent free lunch which others cannot exploit. 
Unfortunately, regulators fail to understand the consequences of this. The EMH does not justify a light touch regulation of too big to fail banks. On the contrary, the no free lunch form of the EMH ought to lead regulators to suspect that an incredibly profitable bank is an incredibly risky bank and therefore needs high levels of capital to mitigate the risk. Thanks to the Modigliani-Miller theorem, much higher capital requirements on the banks have low economic cost.

Finance courses need to teach more about the limits to arbitrage not just in terms of behavioural finance, but in terms of well specified market micro structure with proper attention paid to transaction costs, leverage, and collateral requirements. The important stream of literature linking funding liquidity and market liquidity needs to be part of the core courses in financial markets.

It is equally true that over reliance on the "prices are right" form of the EMH allowed much of modern finance to deviate too far from its micro foundations in terms of well defined fundamentals. Derivative models allow us to compute implied volatility and implied correlations (and if necessary the entire implied risk neutral distribution). These models allow us to start valuing anything without any regard to fundamentals at all. Models then become over calibrated to markets and under grounded in fundamentals. For example, quite often derivative textbooks and courses do not encourage us to ask questions like: what is the fair value of an option if we assume that the underlying is $10 \%$ overvalued in the marketplace.

\subsection{There is no risk free rate}

The existence of a risk free rate is not essential in most finance theories, but it is a very convenient simplification. Until the crisis, this simplification was largely harmless. With the onset of concerns about sovereign debt even in core developed markets, the assumption of a risk free rate is no longer a harmless simplification.

In equity pricing theory, the notion of a risk free rate was dispensed with as long ago as the zero beta model of Black (1972). Moreover, rising levels (and volatility) of inflation in the 1970s led to the realization that the nominal risk free asset is not really risk free.

In fixed income markets, the risk free rate played a more important role as all bonds tended to be priced off the risk free yield curve. In the early 2000s, this changed however and the swap yield curve displaced the sovereign yield curve as the pricing benchmark. During the crisis, the spread between Libor and government bonds reached stratospheric levels. The idea of the swap rate (which is tied to Libor) being risk free became increasingly untenable.

At the same time, it was not possible to go back to the notion of government bonds being risk free. During the crisis, credit default swap (CDS) premia for top rated (AAA) sovereigns rose above 100 basis points. This implied that the annual risk neutral probability of default of these sovereigns was $1 \%$ or more which is hardly compatible with the idea of their bonds being risk free.

Post crisis, OIS (overnight index swap) is regarded as the closest thing to risk free under the assumption that the probability of default of a highly creditworthy entity over a one day horizon is negligible. This leads to the well known two curve discounting model (Fujii, Shimada and Takahashi, 2009 and 2010, Mercurio, 2009 and Morini, 2009). I think the idea of a risk free rate should be regarded as nothing more than a useful approximation.

\subsection{Financial institutions and markets must be reintegrated}

Over the years, finance teaching (and to some extent finance theory) has come to be segmented between Financial Institutions and Financial Markets. This segmentation is increasingly untenable as the dividing line between institutions and markets gets blurred. 
The repo market is a good example of this blurring of lines. Pre crisis, courses on fixed income markets placed a lot of emphasis on the repo market as a critical component of the bond market. But neither the markets courses nor the banking courses looked at the repo market as being akin to a bank or a financial institution. After the crisis, Gorton and Metrick (2009) have taught us that the repo market is a "shadow bank" vulnerable to old fashioned "bank runs" (see also Pozsar et al, 2010).

Similarly, courses in financial markets did not focus much on the fact that banks were investing in securitized instruments through Special Investment Vehicles (SIVs) that funded themselves with Asset Backed Commercial Paper (ABCP). This fragile form of maturity transformation had devastating implications for certain securitization markets during the crisis.

At another level, it is perhaps true that we teach too much of ephemeral institutional detail. Many of the details which we taught to our students during the last 3-5 years have been rendered obsolete by changes in the market structure. Investment banks are gone, the Libor market is barely recognizable and risk free government paper is no longer risk free. When we are preparing students for a career and not for their first job, we must emphasize functions and not institutions; concepts and not context.

\section{Learning from Related Disciplines}

\subsection{Biology and sociology are as important as psychology}

Behavioural finance is now so much a part of most standard finance that it is often difficult to distinguish behavioural and neoclassical finance (Berg and Gigerenzer, 2010). For example, the asset pricing models that include the momentum factor are clearly behavioural finance models, and even the Fama-French model has a strong behavioural interpretation. The limits to arbitrage literature is also often associated with behavioural finance. All these approaches have proved their worth during the crisis.

Yet, there are areas in which there is a need to re-emphasize hard nosed rational models. For example, the build-up to the subprime crisis was characterized by a reliance on credit history (FICO scores). The implicit assumption is that default is a behavioural trait that can be measured using past payment records. Rational models (Merton style models) assume that people default when it is rational to do so and focuses attention on modelling the fundamentals (for example home prices). Clearly lenders would have been much better relying on rational models rather than presumed behavioural traits.

Unfortunately, during the lending boom, behavioural models held sway and these were supported by the short historical time series data that was then available. It is amazing but true that so much of what happened during 2007 and 2008 can be explained as the rational response of economic actors to altered fundamentals.

These divergent signals from the global financial crisis suggest that the right balance between behavioural models and rational models remains a major challenge for finance theory despite the growing synthesis of behavioural and neoclassical finance.

Continuing developments in neural imaging leads me to believe that neurosciences might have a lot to contribute to finance theory (Bernheim, 2008). The sociology of finance is another promising discipline which could improve our understanding of financial markets. In particular, the sociology of knowledge and the literature on market devices as socio-technical systems are particularly important. (Beunza and Stark, 2010 and MacKenzie, 2010). 


\subsection{Econometrics must be grounded in financial history}

The global financial crisis and its aftermath evoked parallels with

- The Great depression of 1930s

- $\quad$ The Panic of 1907

- The sovereign defaults of 1890 s and 1930 s

- The financial (and sovereign debt) crises of 1830 s and 1870 s

From a long historical perspective, the financial crisis does not appear to be an aberration at all. On the contrary, it is the Great Moderation of the late 1990s and early 2000s that appears to be an aberration. For example, Haldane (2009) provides the following data for macro-economic volatility in the UK:

\begin{tabular}{|l|c|c|}
\hline Variable & Volatility (1998-2007) & Volatility (1857-2007) \\
GDP growth & $0.6 \%$ & $2.7 \%$ \\
\hline Earnings growth & $0.5 \%$ & $6.4 \%$ \\
\hline Inflation & $0.9 \%$ & $5.9 \%$ \\
\hline Unemployment & $0.6 \%$ & $3.4 \%$ \\
\hline
\end{tabular}

Table 1: Volatility of UK macroeconomic variables during the Great Moderation compared with 150 year average. Source, Haldane (2009) Annex Table 1.

A key mistake prior to the crisis was the assumption that the Great Moderation was a permanent structural change in the world economy that implied a permanently reduced volatility. The crisis has taught us that the statistical processes that we observe during any particular period should be viewed as just one of several possible regimes. There is always a non trivial probability of shifting to a different regime.

The "new normal" in this sense is that there is no unique and stable "normal." Frequent regime changes imply that sample sizes (restricted to the current regime) are always small. More importantly, the possibility of future regime changes means that the parameters of the historical distribution estimated from such a sample are not reliably predictive of the future distribution. Since regime changes are relatively infrequent, the probability of a regime change is also estimated very imprecisely from past data. As a result, the historical data is never sufficient to completely dominate the subjective prior distribution. Heterogeneous expectations about the future distribution are therefore to be expected.

I see financial history as providing powerful inputs into the econometric procedures that we use. Since high quality data does not usually go back more than a few decades, we do not have the option of fitting econometric models directly to centuries of data. Yet, it is not sensible to limit the estimation process to only the limited sample duration that is available. What we need to do is to favour robust models that are qualitatively consistent with decades if not centuries of historical experience. Such models should not only provide a good fit to the high quality data of the recent past, but also allow us to extrapolate far beyond recent experience. Markov switching models using Bayesian priors are quite capable of doing this in a tractable and elegant way. 
In any case, a significant amount of financial history should be a part of the finance curriculum. Among the many excellent books that are available today, I would like to mention Reinhart, and Rogoff (2009), Homer and Sylla (2005) and Goetzmann and Rouwenhorst (2005).

\subsection{Hard mathematics should not be eschewed}

The mathematical and statistical tools required in post crisis finance are not new - they are the tools that have been widely used in finance theory during the last decade or more. What would be new would be their introduction into the MBA finance curriculum which has tended to be caught in a time warp of the 1980s or even the 1970s. The key elements of a modern curriculum in mathematical finance would include:

- Fat tailed distributions, power laws and copulas

- Bayesian statistics including efficient implementation methods like MCMC (Markov Chain Monte Carlo) methods

- Dragon Kings and Log Periodic Power Laws (Sornette, 2009 and Fantazzini and Geraskin, 2011)

- Stochastic calculus for Levy processes and discontinuous semimartingales (textbook treatments being found in Applebaum, 2004 and Rogers and Williams, 2000)

\subsection{Network models have great potential}

Easley and Kleinberg (2010) provide a powerful framework for looking at markets as networks. Contagion of crises and many other emergent phenomena can perhaps be best understood as network effects. There has been a great deal of effort to understand the interdependence of banks by using network models (Garratt, Mahadeva and Svirydzenka, 2011). I believe that network theory would become an integral part of the toolkit of finance theory and it is time for these tools to enter the finance curriculum.

\section{Conclusion}

The global financial crisis has revealed serious problems with the finance that is taught in a typical MBA programme. One major reason for this is that the coverage in the finance courses has not kept pace with the developments in finance theories in the last decade or more. For example, the global financial crisis demonstrated that risk modelling using Value at Risk with Gaussian distributions and linear correlations is a terrible idea. However, finance theory had moved far beyond this naïve model since the late 1990s. In other words, while a lot needs to change in finance teaching, much less may need to change in finance theory itself.

Another important conclusion is that many ideas that are well understood within certain subfields in finance need to be better assimilated into mainstream models. For example, many concepts in market microstructure cannot remain niche ideas, but must become part of the core toolkit of finance.

Finally, finance theory itself is constantly evolving and needs to draw on insights from several other disciplines to enrich itself. Behavioural finance has succeeded in integrating several models from psychology into mainstream finance, but the global crisis has demonstrated that many phenomena have their roots in sociological factors. Apart from sociology, finance must learn from evolutionary biology, neurosciences, financial history and the multidisciplinary field of network theory. Above all, the increasingly complex world of finance needs more sophisticated mathematical models and statistical tools. 


\section{References}

Acharya and Pedersen (2005), "Asset pricing with liquidity risk", Journal of Financial Economics, 77(2), 375-410.

Amihud and Mendelson (1986) "Liquidity and stock returns" Financial Analysts Journal, May-June, 43-48.

Ang, Andrew, William N. Goetzmann and Stephen M. Schaefer (2009)

"Evaluation of Active Management of the Norwegian Government Pension Fund - Global", Report to the Ministry of Finance, Government of Norway, December 14, 2009, available online at http://www.regjeringen.no/upload/FIN/Statens pensjonsfond/rapporter/AGS Report.pdf

Applebaum, David (2004) Levy Processes and Stochastic Calculus, Cambridge University Press

Barro, R. J. (2006). "Rare Disasters and Asset Markets in the Twentieth Century," Quarterly Journal of Economics, 121, 823-866.

Barro, R. J. and J. F. Ursua (2009) “Stock-Market Crashes and Depressions”, NBER Working Paper 14760 .

Bell, A. M. (2007) “Animal personalities,” Nature, 447, 539-540.

Berg and Gigerenzer (2010) “As-if behavioral economics: Neoclassical economics in disguise?", MPRA Paper No. 26586.

Bernheim, B. Douglas (2008) "Neuroeconomics: A Sober (But Hopeful) Appraisal”, NBER Working Paper 13954, available online at http://www.nber.org/papers/w13954

Beunza, Daniel and Stark, David (2010) "Models, Reflexivity, and Systemic Risk: A Critique of Behavioral Finance". Available at SSRN: http://ssrn.com/abstract=1285054

Black, Fischer (1972) "Capital Market Equilibrium with Restricted Borrowing", The Journal of Business, 45(3), 444-455.

Black, Fischer and Litterman, Robert (1992) "Global Portfolio Optimization," Financial Analysts Journal, September-October 1992, 28-43,

Borch, Karl (1976) "The monster in Loch Ness", Journal of Risk and Insurance,

Brunnermeier and Pedersen (2007), "Market Liquidity and Funding Liquidity," NBER Working Paper No. 12939, February 2007

Buss, D. M. (2009) "How Can Evolutionary Psychology Successfully Explain Personality and Individual Differences?", Perspecitves on Psychological Science, 4(4), 359-366.

Cesarini, David, Christopher T. Dawes, Magnus Johannesson, Paul Lichtenstein, and Bjorn Wallace (2009) "Genetic variation in preferences for giving and risk-taking". Quarterly Journal of Economics, (124):809-842.

Cesarini, David, Magnus Johannesson, Paul Lichtenstein, Orjan Sandewall, and Bjorn Wallace. (2010) "Genetic variation in financial decision-making", Journal of Finance, 65(5), 1725-1754. 
Chen, Zhiwu, Ibbotson, Roger G. and Hu, Wendy , "Liquidity as an Investment Style" Yale SOM Working Paper. Available at SSRN: http://ssrn.com/abstract=1675108

Easley, David and Jon Kleinberg (2010), Networks, Crowds, and Markets: Reasoning about a Highly Connected World, Cambridge University Press.

Fama , E. F. (1963) "Mandelbrot and the Stable Paretian Hypothesis, Journal of Business, 36(4), 420429.

Fantazzini, Dean and Geraskin, Petr (2011), "Everything You Always Wanted to Know About Log Periodic Power Laws for Bubble Modelling But Were Afraid to Ask", European Journal of Finance, Forthcoming. Available at SSRN: http://ssrn.com/abstract=1752115

Fujii, Masaaki, Yasufumi Shimada and Akihiko Takahashi (2009) "A Market Model of Interest Rates with Dynamic Basis Spreads in the presence of Collateral and Multiple Currencies," available at http://ssrn.com/abstract $=1520618$

Fujii, Masaaki, Yasufumi Shimada, and Akihiko Takahashi (2010), "A Note on Construction of Multiple Swap Curves with and without Collateral," available at http://ssrn.com/abstract=1440633

Garratt, Rodney J, Lavan Mahadeva and Katsiaryna Svirydzenka (2011) "Mapping systemic risk in the international banking network", Bank of England Working Paper No. 413 available online at http://www.bankofengland.co.uk/publications/workingpapers/wp413.pdf

Goetzmann, William N. and K. Geert Rouwenhorst (2005) The origins of value: The financial innovations that created modern capital markets, Oxford University Press.

Gorton, Gary B. and Metrick, Andrew (2009), "Securitized Banking and the Run on Repo", NBER Working Paper 15223.

Haldane , Andrew G (2009), "Why banks failed the stress test", Bank of England, available online at www.bankofengland.co.uk/publications/speeches/2009/speech374.pdf

Heilbronner, Sarah R, Alexandra G Rosati, Jeffrey R Stevens, Brian Hare and Marc D Hauser (2008), "A fruit in the hand or two in the bush? Divergent risk preferences in chimpanzees and bonobos", Biol. Lett., 4, 246-249.

Homer, Sidney and Richard E. Sylla (2005) A history of interest rates, John Wiley and Sons.

Kacelnik, Alex and Melissa Bateson (1996) "Risky Theories - The Effects of Variance on Foraging Decisions", Amer. Zool., 36, 402-434.

Lee, Bernard, Shih-Fen Cheng and Annie Koh (2010) "An Analysis of Extreme Price Shocks and Illiquidity among Systematic Trend Followers", Review of Futures Markets, 18:4, 385-419.

Lo, Andrew W. (2004), "The Adaptive Markets Hypothesis: Market Efficiency from an Evolutionary Perspective". Available at SSRN: http://ssrn.com/abstract=602222

Lo, Andrew W. (1999) “The Three P's of Total Risk Management”, Financial Analysts Journal, 55( 1), 13-26. 
MacKenzie, Donald (2010) "The Credit Crisis as a Problem in the Sociology of Knowledge", Available online at http://www.stis.ed.ac.uk/ data/assets/pdf file/0019/36082/CrisisRevised.pdf

Mallaby, Sebastian (2010) More Money than God, Bloomsbury

Mandelbrot, B. (1963) “The Variation of Certain Speculative Prices”, Journal of Business, 36(4), 394419

Markowitz (1952) "Portfolio Selection”, Journal of Finance, 7(1), 77-91.

Mercurio, Fabio (2009) "Interest Rates and The Credit Crunch: New Formulas and Market Models," available at http://ssrn.com/abstract=1332205

Morini, Massimo (2009) "Solving the puzzle in the interest rate market (Part 1 \& 2)," available at http://ssrn.com/abstract=1506046

Pastor and Stambaugh (2003), "Liquidity Risk and Expected Stock Returns", Journal of Political Economy, 111(3), 642-685.

Pozsar, Zoltan, Tobias Adrian, Adam Ashcraft and Hayley Boesky (2010), "Shadow Banking", Federal Reserve Bank of New York Staff Report No 458.

Rajan, Raghuram (2010) Fault Lines: How Hidden Fractures Still Threaten the World Economy, Princeton University Press.

Reinhart, Carmen M. and Kenneth S. Rogoff (2009) This time is different: Eight centuries of financial folly, Princeton University Press.

Rogers, L. C. G. and David Williams (2000), Diffusions, Markov Processes and Martingales, Cambridge University Press

Rosenberg, Barr and James Guy (1976) "Prediction of beta from investment fundamentals", Financial Analysts Journal, May-June 1976, 60-72.

Roubini, Nouriel and Stephen Mihm (2010) Crisis economics: A crash course in the future of finance, Penguin Press

Salmon, Felix (2009) "Recipe for Disaster: The Formula That Killed Wall Street", Wired Magazine, 17(3), available online at http://www.wired.com/techbiz/it/magazine/17-03/wp quant?currentPage=all

Shiller, Robert J. (2008) The subprime solution: How today's global financial crisis happened, and what to do about it, Princeton University Press.

Sornette, Didier (2009) "Dragon-Kings, Black Swans and the Prediction of Crises", International Journal of Terraspace Science and Engineering, 2(1), 1-18

Sharpe, W. F. (1964) "Capital Asset Prices: A Theory of Market Equilibrium under Conditions of Risk”, Journal of Finance, 19(3), 425-442.

Smith, Yves (2010) ECONned: How unenlightened self interest undermined democracy and corrupted capitalism, Palgrave Macmillan 
Thaler, R. H. (1999) “The End of Behavioral Finance”, Financial Analysts Journal, 55(6), 12-17

Treynor, Jack L. and Fischer Black (1973) "How to use security analysis to improve portfolio selection", Journal of Business, 46(1), 66-86.

Varma, Jayanth R. (2009) "Risk Management Lessons from the Global Financial Crisis for Derivative Exchanges", IIMA Working Paper No. 2009-02-06. Available at SSRN: http://ssrn.com/abstract=1376276

Wolf, Max, G. Sander van Doorn, Olof Leimar and Franz J. Weissing (2007) "Life-history trade-offs favour the evolution of animal personalities", Nature, 447, 581-585. 